\title{
ÁREA DE HEXÁGONOS ATRAVÉS DA DECOMPOSIÇÃO EM TRIÂNGULOS: UM ESTUDO A PARTIR DO SOFTWARE GEOGEBRA
}

\author{
Juliana Gabriele Kiefer, UFSM, juliana_kiefer@hotmail.com \\ Rita de Cássia Pistóia Mariani, UFSM, rcpmariani@yahoo.com.br \\ Maria Arlita da Silveira Soares, Unipampa, arlitasoares@gmail.com
}

\begin{abstract}
Resumo
Este artigo tem por objetivo investigar se e como licenciandos em Matemática mobilizam representações semióticas ao realizarem uma atividade adaptada da Olimpíada Brasileira de Matemática das Escolas Públicas (OBMEP), que explora área de hexágonos a partir da decomposição em triângulos, com o apoio do software GeoGebra. Para tanto, toma-se como aporte teórico os Registros de Representação Semiótica (RRS). A pesquisa caracteriza-se como qualitativa e segue pressupostos da Análise de Conteúdo. Os resultados indicam que as apreensões sequencial, perceptiva, discursiva e operatória foram mobilizadas, sendo que a perceptiva e a operatória foram as mais enfatizadas. Além disso, o software auxiliou de modo expressivo na resolução da atividade, pois tornou a atividade dos alunos mais experimental e exploratória, possibilitando a mobilização das representações semióticas.
\end{abstract}

Palavras-chave: área; registros de representação semiótica; apreensões; GeoGebra.

\section{HEXAGONS AREA THROUGH THE TRIANGLES DECOMPOSITION: A STUDY USING THE GEOGEBRA SOFTWARE}

\section{Abstract}

This article aims to investigate whether and how undergraduates in Mathematics mobilize semiotic representations when carrying out an adapted activity from the Brazilian Mathematics Olympiad of Public Schools (OBMEP), which explores the hexagons area from the decomposition into triangles, with the support of the GeoGebra software. For that, the Registers of Semiotic Representation (RRS) were used as theoretical reference. The research is characterized as qualitative and follows the premises of Content Analysis. The results indicate that sequential, perceptual, discursive and operative apprehensions were mobilized, with perceptual and operative apprehensions being the most emphasized. In addition, the software significantly helped to solve the activity, as it made the students activities more experimental and exploratory, making possible the mobilization of the semiotic representations.

Keywords: area; semiotic representation registers; apprehensions; GeoGebra.

\section{Introdução}

O conceito de área de figuras planas é importante para a formação dos estudantes, tanto por sua relação com o cotidiano, quanto por possibilitar articulações com outros campos da matemática, como a Geometria e a Aritmética ou, ainda, através de conexões com outros campos do conhecimento (Lima; Bellemain, 2010). No âmbito do processo de ensino e aprendizagem, orientações curriculares (Brasil, 1997, 1998, 2018) sugerem que esse conceito seja abordado desde os anos iniciais do Ensino Fundamental, com maior ênfase nos anos finais e o estudo não sendo reduzido a mera aplicação de fórmulas para o cálculo de área, privilegiando atividades que utilizem composição e decomposição de figuras. Por exemplo, dentre os objetos de estudo, sugeridos pela Base Nacional Comum Curricular (Brasil, 2018, p. 308) para o $7^{\circ}$ ano 
dos anos finais, está a "Equivalência de área de figuras planas: cálculo de áreas de figuras que podem ser decompostas por outras, cujas áreas podem ser facilmente determinadas como triângulos e quadriláteros". A partir disso, evidencia-se a pertinência de explorar o conceito de área com auxílio de "outras estratégias" e não apenas o uso mecânico de fórmulas. "É de fundamental importância também considerar o papel heurístico das experimentações na aprendizagem matemática [...]" (Brasil, 2018, p. 265).

Nesse sentido, uma das teorias de aprendizagem que visa explorar o papel heurístico das figuras é a dos Registros de Representação Semiótica (RRS), desenvolvida, inicialmente, por Raymond Duval. Para ele, ao se trabalhar com conceitos geométricos, há a necessidade de mobilizar registros figurais e em língua natural, simultaneamente. Os figurais são empregados para visualização e reconhecimento de algumas das propriedades do objeto matemático em questão e os em língua natural são utilizados para enunciar definições, teoremas, hipóteses, etc. (Duval, 2009).

De acordo com Duval (2003), para a compreensão conceitual de um objeto matemático (noésis) tem-se a necessidade da produção ou apreensão de uma representação semiótica (semiósis). Em relação a esta, existem três atividades cognitivas essenciais: formação, que constitui um traço ou um ajuntamento de traços perceptíveis com o intuito de identificar uma representação de alguma coisa em determinado sistema; transformação de tratamento, que consiste na transformação interna de um registro, ou seja, a representação inicial é transformada em outra, conservando o mesmo tipo de registro; transformação de conversão, que consiste na transformação de uma representação em outra, conservando a totalidade ou parte do conteúdo da representação inicial.

Os Parâmetros Curriculares Nacionais e a Base Nacional Comum Curricular (Brasil, 1997, 1998, 2018) também salientam que o uso de recursos tecnológicos, em especial, softwares, pode trazer significativas contribuições para (re)pensar o processo de ensino e aprendizagem de Matemática, principalmente, no que tange as representações, pois evidencia o importante papel da linguagem gráfica bem como das diferentes formas de representação na elaboração de estratégias para a abordagem de determinados problemas (Brasil, 1998). Entretanto, não basta apenas usar esses recursos, é preciso planejar ações a partir de pressupostos de teorias de aprendizagens.

Deste modo, tendo em vista a importância de se trabalhar o conceito de área não apenas com a utilização de fórmulas, bem como as contribuições do uso dos softwares e, ainda, considerando os licenciandos em Matemática como futuros professores que irão desenvolver atividades relacionadas a esse conceito com seus alunos futuramente, $o$ objetivo deste trabalho é investigar se e como licenciandos em Matemática mobilizam representações semióticas ao realizarem uma atividade adaptada da Olimpíada Brasileira de Matemática das Escolas Públicas (OBMEP), que explora área de hexágonos a partir da decomposição de triângulos, com apoio do software GeoGebra.

\section{Software no ensino e aprendizagem de Geometria: um olhar a partir dos Registros de Representação Semiótica}

O debate sobre a utilização de softwares no processo de ensino e aprendizagem de Matemática, em particular, de Geometria, ocupa considerável espaço de discussão nos meios acadêmicos (Sena; Dorneles, 2013), intensificado com a publicação de orientações curriculares (Brasil, 1998, 2018). Duval (2013) destaca observações importantes sobre o uso de softwares, a saber: as representações que eles exibem são as mesmas produzidas graficamente no papel para uma apreensão visual; eles constituem um modo fenomenológico de produção radicalmente novo, fundamentado na aceleração 
de tratamentos, ou seja, obtêm-se imediatamente muito mais que tudo o que se poderia obter a mão livre; as representações semióticas não discursivas (figuras geométricas, gráficos cartesianos) tornam-se manipuláveis como objetos reais, ou seja, pode-se deslocar, fazer rodar, ou estender objetos matemáticos a partir de um ponto, principalmente, objetos geométricos.

Os softwares, além de possibilitarem procedimentos heurísticos, permitem uma abordagem "experimental" de relações e de propriedades geométricas (Duval, 2013). Jahn e Bongiovanni (2019, p. 256) destacam a disponibilidade de "[...] diversas ferramentas que representam relações e transformações geométricas e permitem, de forma bastante direta e econômica, observá-los e tratá-los com novos elementos e/ou modificações gráfico espaciais, inacessíveis no contexto do papel\&lápis".

De acordo com Basso e Notare (2015, p. 5), "A exploração de figuras e de suas propriedades dá origem ao reconhecimento de um sistema de relações geométricas, que em última análise constituem o objeto geométrico". Nesse sentido, Jahn e Bongiovanni $(2019$, p. 256) ressaltam que o caráter dinâmico desses ambientes "[...] e as ferramentas neles disponíveis permitem uma exploração mais direta das figuras, favorecendo a visualização de outros elementos e de subfiguras que podem auxiliar os alunos na resolução de problemas".

Ao considerar os RRS, no que tange aos softwares, Salazar e Almouloud (2015) ampliaram os estudos de Duval em relação às atividades cognitivas essenciais (formação, tratamento e conversão) no ambiente de geometria dinâmica (AGD). No que se refere à transformação de tratamento dinâmica considera-se três tipos: mudar $a$ posição (por meio da manipulação direta, o sujeito pode modificar de maneira instantânea a posição da figura representada na área de trabalho, conservando sua forma); mudar o comprimento dos lados (utiliza-se a função de arrastamento e também pode-se utilizar a ferramenta de homotetia); reconfigurar (utilizam-se as ferramentas do AGD necessárias, dependendo da figura e do problema a resolver, para separar, reagrupar ou formar outra figura a partir de uma configuração inicial).

Em relação à conversão no AGD, Salazar e Almouloud (2015) destacam a conversão da representação no registro figural para a representação no registro em língua natural, afirmando que, neste tipo de conversão, existem dois casos distintos: a ilustração e a descrição. A primeira refere-se à conversão de uma representação em língua natural para uma representação figural, já a segunda seria a conversão inversa. Além disso, a ilustração não é uma conversão que permite solucionar uma tarefa complexa, ela apoia o sujeito no processo de resolução de um problema, enquanto que a descrição permite que o sujeito realize conjecturas sobre a figura representada.

Além da importância das transformações, tratamento e conversão, ao considerar os registros figurais e discursivos destaca-se, também, as apreensões figurais (Duval, 2012). Estas tratam das interpretações que o sujeito em interação pode ter em relação as diversas formas as quais as figuras podem ser representadas, tendo em vista que, em geometria, consideram-se as figuras que possuem propriedades a serem exploradas. Sendo consideradas quatro apreensões: sequencial, perceptiva, discursiva e operatória.

A apreensão sequencial é solicitada em problemas que requerem construção ou descrição, cujo objetivo é a reprodução de uma figura. A apreensão perceptiva está relacionada a identificação imediata das formas. A apreensão discursiva consiste na interpretação dos elementos da figura, enfatizando a articulação dos enunciados, ou seja, "[...] corresponde a uma explicitação de outras propriedades matemáticas da figura, além daquelas indicadas por uma legenda ou pelas hipóteses do enunciado" (Jahn e Bongiovanni, 2019, p. 245). E, a apreensão operatória está relacionada as modificações que podem ocorrer em uma figura e suas reorganizações. 
As modificações ocorridas classificam-se em mereológica (a figura inicial é dividida em unidades figurais de mesma dimensão), ótica (a figura inicial é aumentada ou diminuída) e posicional (são preservados o tamanho e a forma da figura de partida, o que varia é a orientação, por exemplo, deslocamento, translação, rotação e reflexão da figura). Cabe ressaltar que, a modificação mereológica é subdividida em três tipos: estritamente homogênea (as partes obtidas possuem a mesma forma que o todo), homogênea (as partes obtidas são iguais entre si, mas possuem forma diferente da figura de partida) e, heterogênea (as partes obtidas são diferentes entre si).

\section{Escolhas metodológicas}

A presente pesquisa é caracterizada como qualitativa, pois busca contextualizar o fenômeno investigado, a problemática levantada, ou ainda, a ocorrência de acontecimentos. Cabe ressaltar que, os dados iniciais foram produzidos em uma pesquisa realizada pela primeira autora, desenvolvida no âmbito do EMgep (Educação Matemática: grupo de estudos e pesquisas).

Os sujeitos participantes foram acadêmicos matriculados no componente curricular Recursos Tecnológicos no Ensino da Matemática II, do Curso de Matemática Licenciatura da Universidade Federal de Santa Maria (UFSM). Tal escolha justifica-se em função do alinhamento das ações de investigação com os objetivos elencados para esse componente curricular: "Analisar recursos tecnológicos com relação à possibilidade de utilização no ensino fundamental e médio. Planejar aulas utilizando tecnologias de informação e comunicação" (PPC/Matemática/UFSM, 2014).

A dinamização da atividade se deu no horário regular das aulas e contou com a participação de oito acadêmicos, os quais tinham a possibilidade de se organizarem em duplas ou individualmente. Deste modo, considerando a preservação dos preceitos éticos da pesquisa, os protocolos dos sujeitos foram identificados por letras maiúsculas do alfabeto latino: D, F, G (duplas) e H e I (individuais).

A análise dos dados seguiu os princípios da Análise de Conteúdo (Bardin, 2016), sendo considerados três pólos cronológicos: pré-análise, exploração do material, e, tratamento dos resultados e interpretações. Na pré-análise, segundo Bardin (2016), ocorre a seleção e adaptação da atividade a ser desenvolvida. Para tanto, a escolha se deu a partir do banco de questões das provas da OBMEP, da primeira fase (questões objetivas) para o nível 2 (correspondente aos $8^{\circ}$ e $9^{\circ}$ anos). A questão (Quadro 1) foi selecionada por envolver o conceito de área, bem como, possibilitar a decomposição das figuras envolvidas.

Quadro 1 - Questão original e possível resolução

\begin{tabular}{|c|c|}
\hline Questão Original & Possível resolução \\
\hline $\begin{array}{l}\mathrm{Na} \text { figura, dois vértices do } \\
\text { hexágono regular maior coincidem } \\
\text { com dois vértices do hexágono } \\
\text { regular menor. O hexágono menor } \\
\text { tem área igual a } 10 \mathrm{~cm}^{2} \text {. Qual é a } \\
\text { área do hexágono maior? } \\
\text { a) } 20 \mathrm{~cm}^{2} \\
\text { b) } 30 \mathrm{~cm}^{2} \\
\text { c) } 35 \mathrm{~cm}^{2} \\
\text { d) } 36 \mathrm{~cm}^{2} \\
\text { e) } 40 \mathrm{~cm}^{2}\end{array}$ & $\begin{array}{l}\text { Mobilizar a apreensão operatória para decompor o hexágono } \\
\text { menor em seis triângulos equiláteros, observando que a região de } \\
\text { sobreposição dos dois hexágonos possui área de duas metades de } \\
\text { um desses triângulos equiláteros, ou seja, um triângulo equilátero } \\
\text { inteiro, com área medindo } \frac{10}{6} \mathrm{~cm}^{2} \text {. Em seguida, dividir o hexágono } \\
\text { maior em triângulos congruentes ao } \\
\text { triângulo de sobreposição. Desta forma, o } \\
\text { hexágono maior é decomposto em } 18 \\
\text { triângulos e, portanto, sua área é } 18 \times \\
\frac{10}{6}=30 \mathrm{~cm}^{2} \text {. }\end{array}$ \\
\hline
\end{tabular}

Fonte: Dados da pesquisa. 
Ao analisar o enunciado da questão original observa-se registros em língua natural e figural. Cabe ressaltar uma informação muito importante em relação aos hexágonos, a de serem regulares, o que é evidenciado no discurso e não na figura. $\mathrm{Na}$ possível resolução, observa-se a utilização da apreensão operatória mereológica homogênea, na qual os triângulos obtidos são congruentes entre si, mas não possuem a mesma forma da figura inicial, ou seja, o hexágono.

A adaptação realizada desta questão se deve ao fato de buscar explorar mais aspectos desta questão, ou seja, mais apreensões e transformações cognitivas. Além disso, com o apoio do software GeoGebra os tratamentos passaram a ser dinâmicos, possibilitando assim a "rapidez" nos movimentos. A questão adaptada (Figura 1) foi denominada Explorando hexágonos. Ela é composta por quatro itens, cinco subitens e dois arquivos $g g b$ (ARQUIVO $12^{1}$, ARQUIVO $13^{2}$ ).

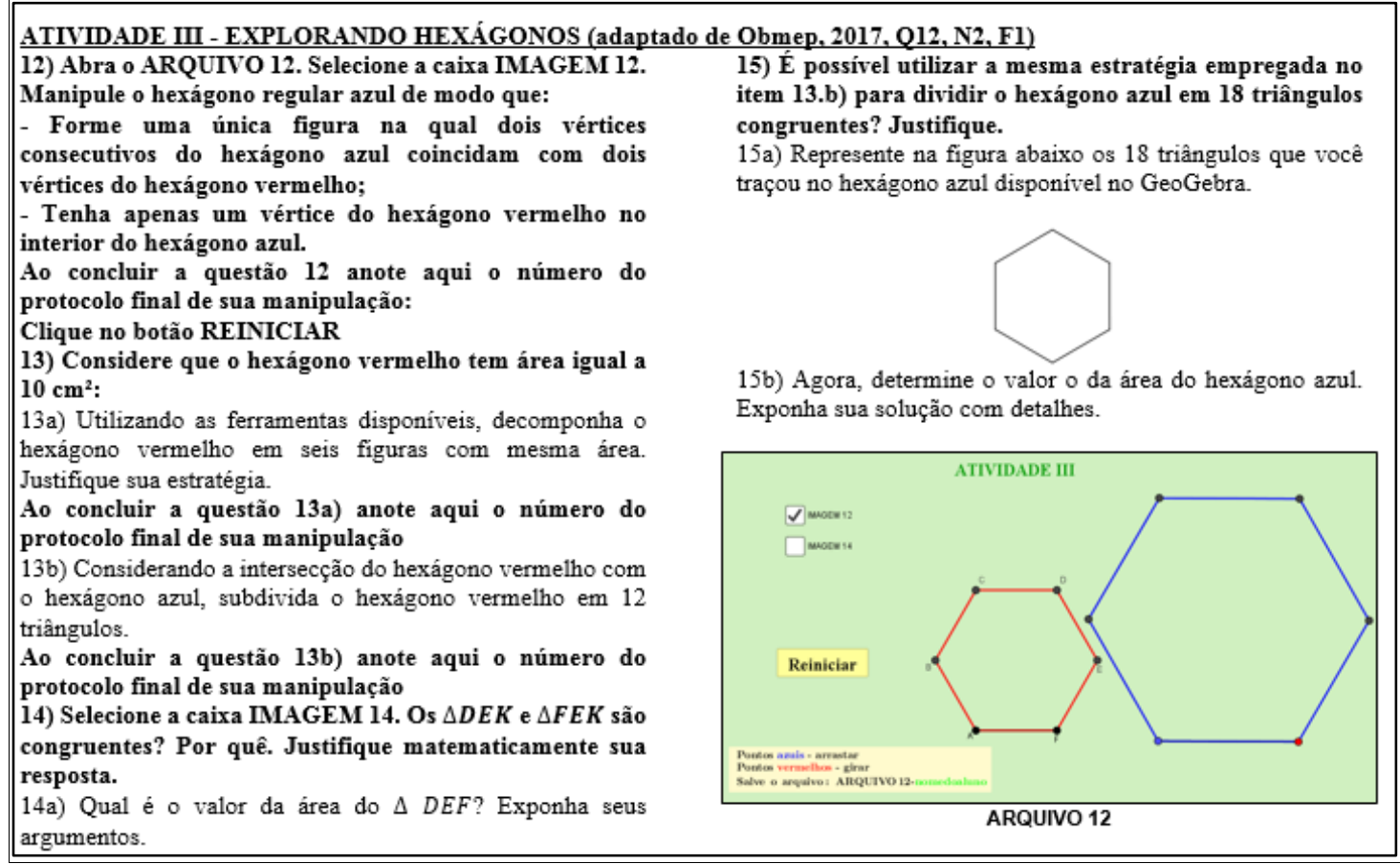

Figura 1 - Questão adaptada

Fonte: Dados da pesquisa.

O primeiro arquivo é utilizado no item 12 da atividade, em que é necessário manipular, através da ferramenta arraste, o hexágono regular azul de modo que satisfaça as condições descritas no enunciado. Desse modo, é preciso compor uma ilustração a partir de translações e rotações de um dos hexágonos. Esse tratamento figural é otimizado pelos recursos disponíveis no GeoGebra e muito difícil de ser realizado com lápis e papel, a ponto de a questão, contida na prova da OBMEP, expor essa composição figural pronta em seu enunciado.

Já o segundo arquivo é utilizado para todos os demais itens da atividade, sendo que, neste arquivo, a composição exigida no item 12 da atividade adaptada, em relação aos dois hexágonos, já está pronta. No recurso são disponibilizadas, no menu superior, ferramentas de construção de segmentos utilizadas para definir as divisões. Buscou-se explorar tratamentos figurais, conversões e apreensões. Entretanto, alguns itens requeriam maior ênfase em alguns dos aspectos, por exemplo, nos itens 13 e 15 em que

${ }^{1}$ O ARQUIVO 12 está disponível para acesso em https://www.geogebra.org/classic/YP678Ua2

2 O ARQUIVO 13 está disponível para acesso em https://www.geogebra.org/classic/aCGYCHXM

V. $18 \mathrm{~N}^{\mathrm{o}} 1$, julho, 2020 RENOTE

DOI: 
buscou-se explorar, de modo especial, as apreensões perceptiva e operatória e no item 14 a apreensão discursiva.

Na segunda fase da Análise de Conteúdo, exploração do material, ocorre a sistematização das decisões tomadas na fase inicial. Nesta pesquisa, ocorreu o desenvolvimento da atividade com os sujeitos participantes bem como a análise das respostas apresentadas. As repostas foram classificadas em satisfatórias, parcialmente satisfatórias ou não satisfatórias. Além disso, foram analisadas quanto à mobilização das apreensões e, também, em relação às transformações cognitivas de tratamento e conversão. Na seção seguinte são expostos o tratamento dos dados e interpretações dos itens 13a), 13b), 15a) e 15b), tendo em vista serem estes que abordam a decomposição dos hexágonos em triângulos.

\section{TRATAMENTO DOS DADOS E INTERPRETAÇÕES}

No tratamento dos resultados e interpretações, segundo Bardin (2016), ocorre a sistematização dos resultados a fim de torná-los válidos e significativos. Neste estudo, são apresentados os resultados obtidos após o desenvolvimento da atividade pelos acadêmicos.

No item 13a), verificou-se que todos os acadêmicos, utilizando as ferramentas de construção de segmentos, seccionaram o hexágono vermelho em seis figuras de mesma área, mobilizando a transformação dinâmica de reconfiguração a partir da apreensão operatória mereológica homogênea. Além disso, utilizaram a ferramenta intersecção para marcar o ponto de intersecção dos segmentos, pois seria necessário indicar tais pontos durante a realização das justificativas solicitadas no item.

Entretanto, observou-se que as justificativas utilizadas nos protocolos $\mathrm{G}, \mathrm{H}$ e I expõem argumentos categorizados como parcialmente satisfatórios, pois descreveram apenas procedimentos de secção da figura, sem mencionar que os triângulos obtidos possuíam, de fato, a mesma área. Indica-se, assim, a mobilização da apreensão sequencial: "Como o hexágono possui 6 vértices, optei por ligar os segmentos dois a dois pelos pontos opostos do centro deste hexágono. Transformando então o hexágono em 6 pequenos triângulos" (Extrato Protocolo I).

Já o protocolo D apresentou indícios da apreensão discursiva ao justificar a congruência dos triângulos: "Todos os 6 triângulos formados são congruentes. Possuem lado comum $\overline{C D}=\overline{D E}=\overline{E F}=\overline{F A}=\overline{A B}=\overline{B C}$ também $\overline{C P}=\overline{P D}=\overline{P E}=\overline{P F}=$ $\overline{P A}=\overline{P B}$. Logo, pelo caso LLL de congruência todos os triângulos são congruentes e assim possuem mesma área”. (Extrato protocolo D). Cabe destacar que, tais argumentos não foram considerados totalmente satisfatórios, pois seria necessário expor maiores informações para que fosse possível realizar algumas das conclusões, tais como, por que podemos afirmar a congruência de alguns segmentos.

Em relação aos dados apresentados pelo protocolo $\mathrm{F}$, verificou-se que a dupla de acadêmicos utilizou a mesma justificativa para os itens 13a) e 13b) com argumentos mais elaborados, dando indícios de mobilização da apreensão discursiva ao explorar propriedades matemáticas de elementos visualizados na seção do hexágono menor, como, por exemplo, o fato de $\overline{A R}$ ser a diagonal do retângulo $A P R S$ e, desse modo, $\triangle A R P \equiv \triangle A R S$ (Figura 2). 


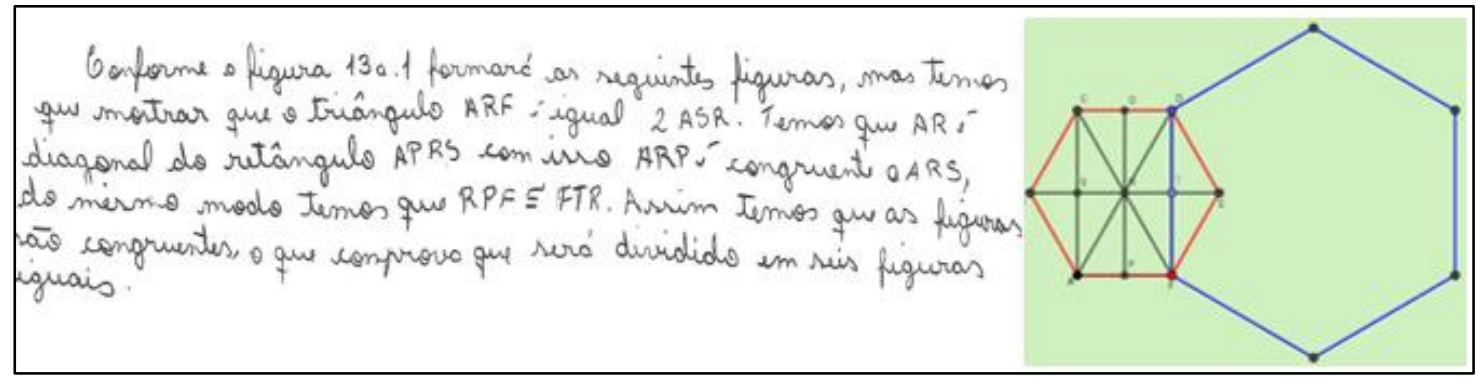

Figura 2 - Resposta do Protocolo F, item 13 a), Atividade III

Fonte: Dados da pesquisa.

As resoluções esperadas para o item 13b) estão expostas na Figura 3, itens (a) e (b). Na Figura 3(a) a estratégia utilizada é traçar segmentos cujas extremidades são dois vértices não consecutivos. Já na Figura 3(b) considera-se segmentos paralelos ao segmento de intersecção.

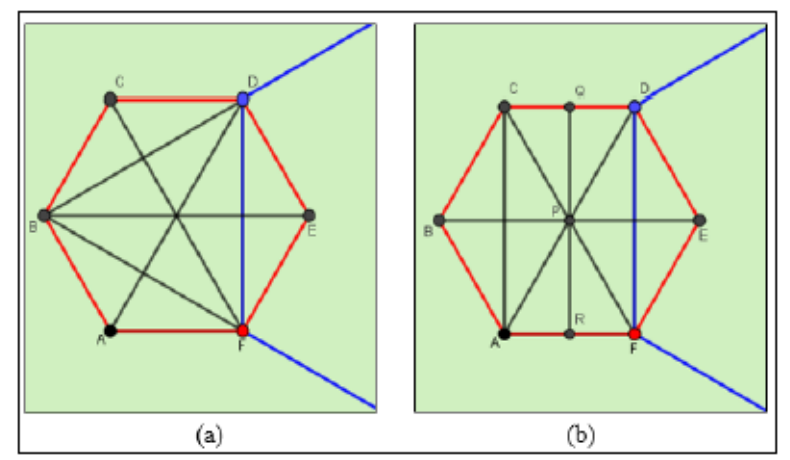

Figura 3 - Possíveis resoluções, item 13 b), Atividade III Fonte: Dados da pesquisa.

Ao analisar os protocolos dos acadêmicos no item 13b), constatou-se desempenho satisfatório em três deles, a saber: D, F e H, sendo que a estratégia utilizada por todos foi a mesma, ou seja, a de considerar segmentos paralelos ao segmento de intersecção. Destaca-se o tratamento dinâmico de reconfiguração, bem como, a conversão dinâmica do tipo ilustração. Nos demais protocolos ( $\mathrm{G}$ e I), verificou-se que os acadêmicos conseguiram dividir o hexágono vermelho em 12 triângulos, mas apresentaram solução equivocada, pois não consideraram a interseção dos dois hexágonos (Figura 4). Tais participantes utilizaram, conforme descrito em sua resposta, a ferramenta ponto médio, ao contrário dos demais participantes.

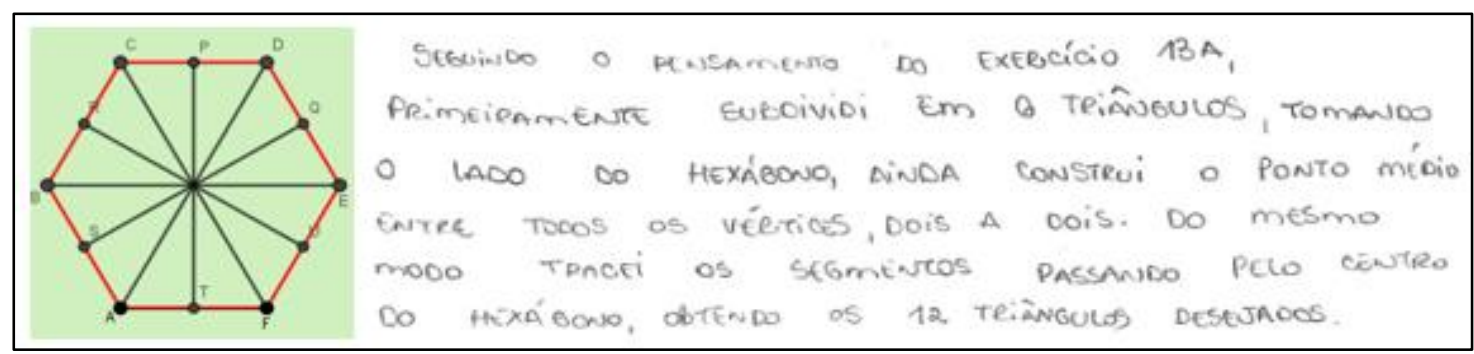

Figura 4 - Resposta do Protocolo I, item 13 b), Atividade III Fonte: Dados da pesquisa.

Em relação à análise do item 15 , evidenciou-se, em todos os protocolos, que não seria possível utilizar a mesma estratégia empregada no item 13b) para dividir o hexágono azul em 18 triângulos congruentes. Já em relação ao item 15a), verificou-se V. $18 \mathrm{~N}^{\circ} 1$, julho, 2020 RENOTE DOI: 
que nos cinco protocolos foram apresentadas quatro maneiras diferentes de dividir um hexágono regular em 18 triângulos (Figura 5), sendo que os protocolos $\mathrm{G}$ e I foram os únicos que continham solução semelhante.

Outro ponto a ser destacado refere-se à utilização de distintas ferramentas do software, a exemplo, o protocolo I apresenta não apenas a ferramenta para traçar segmentos, mas, também, a ferramenta de régua e compasso para realizar a construção requerida, indicando assim a mobilização da apreensão sequencial.

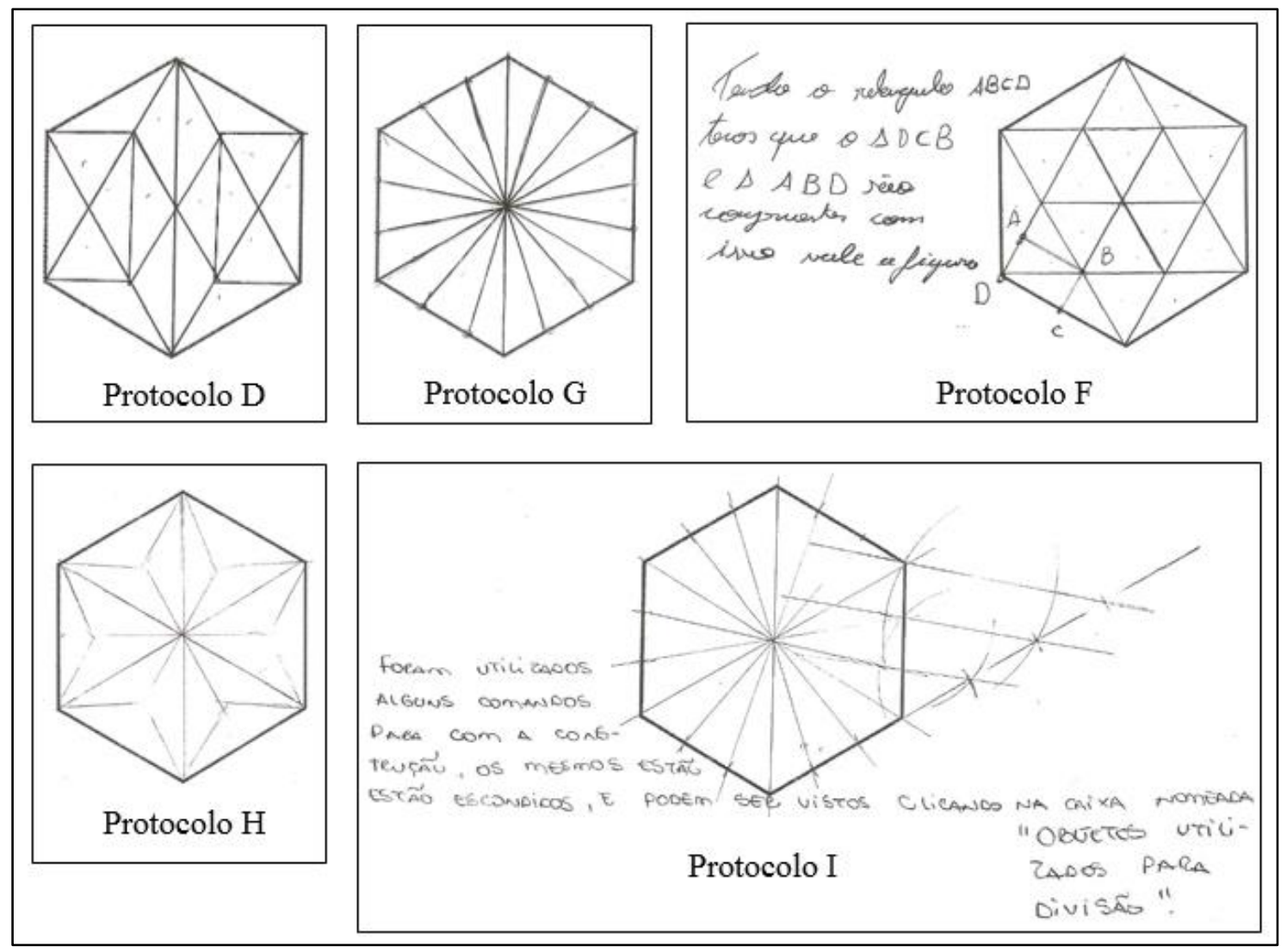

Figura 5 - Respostas do item 15a), Atividade III Fonte: Dados da pesquisa.

Em relação à secção do hexágono constatou-se, nos protocolos $\mathrm{D}$ e $\mathrm{F}$, a mobilização da apreensão operatória mereológica heterogênea, ou seja, as partes obtidas após as divisões não possuíam a mesma forma em relação à figura original (hexágono), nem a mesma forma entre elas. Já nos protocolos G, H e I, a apreensão operatória homogênea foi mobilizada. Além disso, o protocolo $\mathrm{G}$ contém indícios de mobilização da apreensão sequencial, pois a divisão do hexágono azul em 18 triângulos ocorreu através de tratamentos figurais, utilizando os comandos de régua e compasso do GeoGebra.

$\mathrm{Na}$ análise do item 15b), verificou-se que, com exceção do participante I, todos os demais conseguiram determinar a medida da área do hexágono azul. Nos protocolos $\mathrm{F}$ e $\mathrm{H}$, identificou-se um desencadeamento lógico com mais argumentos por meio do registro em língua natural, dando indícios da mobilização da apreensão discursiva: "Como dividimos o hexágono azul em 18 triângulos congruentes, os $\triangle D E F$ temos que a sua área será igual a $\frac{10}{6} \cdot 18=30 \mathrm{~cm}^{2}$ " (Extrato Protocolo $\left.\mathrm{H}\right)$.

Já no protocolo $\mathrm{D}$, os argumentos apresentados restringiram-se ao registro numérico. Além disso, considerou-se que a solução apresentada no protocolo G, embora 
estivesse correta numericamente, não foi embasada em uma justificativa adequada, pois foi expresso que "[...] o hexágono vermelho contém $18 \triangle D E F$ " (Protocolo G_15b), entretanto, de acordo com a ilustração, tais triângulos não são congruentes.

Cabe ressaltar, ainda, que, para realizar tal procedimento numérico, ou seja, de considerar a área do $\triangle D E F$, seria necessário concluir que a área de cada um dos triângulos construídos no hexágono vermelho é a mesma do $\triangle D E F$. Entretanto, as respostas apresentadas pelos participantes foram sucintas, privilegiando o aspecto numérico.

As ferramentas disponíveis no software possibilitaram aos acadêmicos observar o hexágono em diferentes posições e incrementar elementos para dividi-lo em subfiguras que auxiliaram na resolução do problema. Em outros termos, as ferramentas disponíveis no software possibilitaram de forma rápida e econômica, comparado a lápis e papel, modificar a figura dada de modo a visualizar outros elementos fundamentais a resolução do problema. Destaca-se que, "a capacidade de modificar uma figura de partida para ter uma melhor ideia da resolução" (Jahn e Bongiovanni, 2019, p. 256) é fundamental na aquisição de conceitos geométricos.

\section{Considerações finais}

As questões da OBMEP são ricas no aspecto heurístico, cabendo ao professor selecionar e verificar de que modo podem ser exploradas em sala de aula. Neste sentido, observa-se a pertinência deste estudo com futuros professores de Matemática, pois segundo Junior e Cyrino (2009) em cursos de licenciatura em Matemática podem ser oferecidos momentos nos quais os licenciandos tenham a oportunidade de explorar conteúdos de matemática escolar por meio da realização de tarefas com o uso de tecnologias.

Neste artigo, foi apresentada uma proposta de adaptações, que entende-se, assim como os sujeitos participantes, ser possível de trabalhar com alunos dos anos finais do Ensino Fundamental. Ressalta-se que, na atividade, a utilização do software permitiu aos acadêmicos a exploração direta de figuras geométricas, favorecendo a realização de procedimentos heurísticos essenciais a resolução do problema.

Sublinha-se a pertinência entre os referenciais teórico e metodológico adotados, uma vez que os participantes mobilizaram as apreensões figurais e demonstraram reconhecer a importância destas, mesmo sem a explicitação clara da nomenclatura utilizada na teoria dos RRS. As apreensões sequencial, perceptiva, discursiva e operatória foram mobilizadas, com destaque à perceptiva e à operatória. Nesse sentido, corrobora-se com Jahn e Bongiovanni (2019, p. 251) em relação ao uso dos AGD, em específico os softwares, pois "[...] podem auxiliar fortemente no desenvolvimento desse tipo de apreensão [operatória], tornando a atividade dos alunos mais experimental e exploratória, de modo a observar a figura em diversas posições, bem como incrementála com diversos elementos".

Além disso, verifica-se modos distintos de modificar a figura o que "[...] pode contribuir para eliminar a crença de que a resolução de uma questão de Geometria é única e corresponde apenas àquela esperada ou indicada pelo professor" (Jahn; Bongiovanni, 2019, p. 251). Outro ponto a considerar refere-se às conversões dinâmicas de descrição, pois, embora tenham sido mobilizadas, acredita-se na pertinência de explorá-las de modo mais enfatizado, uma vez que, as respostas obtidas, pela maioria dos participantes, foram sucintas e em alguns casos restringindo-se ao aspecto numérico.

\section{Referências}

V. $18 \mathrm{~N}^{\mathrm{o}} 1$, julho, 2020 RENOTE

DOI: 
BARDIN, L. Análise de Conteúdo. São Paulo: Edições 70, 2016.

BASSO, M. V. A; NOTARE, M. R. (2015). Pensar-com Tecnologias Digitais de Matemática Dinâmica. Revista Novas Tecnologias na Educação, v. 13, n. 2, 1-10.

BRASIL, S.E.F. Parâmetros Curriculares Nacionais: Matemática $1^{\circ}$ e $2^{\circ}$ ciclos. Brasília: MEC/SEF, 1997.

BRASIL, S.E.F. Parâmetros Curriculares Nacionais: Matemática $3^{\circ}$ e $4^{\circ}$ ciclos. Brasília: MEC/SEF, 1998.

BRASIL, MEC. Base Nacional Comum Curricular. Brasília, 2018.

DUVAL, R. Registros de representações semióticas e funcionamento cognitivo da compreensão em matemática. Campinas, São Paulo: Papirus, 2003.

DUVAL, R. Semiósis e pensamento humano: Registros semióticos e aprendizagens intelectuais. Trad. Lênio Fernandes Levy e Marisa Rosâni Abreu da Silveira. São Paulo: Editora Livraria da Física, 2009.

DUVAL, R. Registros de representação semiótica e funcionamento cognitivo do pensamento. Tradução: Méricles Thadeu Moretti. Revista Eletrônica de Educação Matemática - Revemat: Florianópolis, v.07, n.2, p. 266-297, 2012.

DUVAL, R. Entrevista: Raymond Duval e a Teoria dos Registros de Representação Semiótica. Concedida a FREITAS, de. J. L. M.; REZENDE, V. Revista Paranaense de Educação Matemática, Campo Mourão, v. 2, n. 3, 2013.

JAHN, A.P; BONGIOVANNI, V. Apreensão Operatória de Figuras em Situações Geométricas. JIEEM v.12, n.3, p. 245-257, 2019.

JUNIOR, J. G.M, CYRINO, M. C. C. T. Propostas de articulação entre teoria e prática em cursos de licenciatura em matemática. Educação Matemática Pesquisa. v.11, p.535 - 557, 2009.

LIMA, P, F. BELLEMAIN, P. M. B. Grandezas e medidas. In: Matemática: Ensino Fundamental. Brasília: Secretaria da Educação Básica, v. 17, 2010.

SALAZAR, J. V. F.; ALMOULOUD, S. A. Registro Figural no ambiente de Geometria dinâmica. Educação Matemática Pesquisa (Online), v. 17, p. 919-941, 2015.

SENA, R. M.; DORNELES, B. V. Ensino de Geometria: Rumos da Pesquisa (19912011). REVEMAT. Florianópolis, v.8, n.1, p.138-155, 2013.

UFSM, Curso de Licenciatura Matemática. Ementa currículo Recursos Tecnológicos No Ensino de Matemática II. (2014). 